hippocampus, and cerebellum. A similar distribution is found after cerebral hypoxia or oligaemia. Hypoglycaemia has several secondary biochemical effects, one of the most dangerous being hyperkalaemia, which may lead, as it did in this patient, to electrocardiographic changes indicating hyperkalaemic damage. This may lead to ventricular fibrillation, but was fortunately reversed by intravenous calcium gluconate and rectal sodium polystyrene sulphonate (Resonium A) on this occasion. It is not unreasonable to suppose that some of the 15 to 20 children who die each year after adenotonsillectomy die from the effects of unrecognised hypoglycaemia.

A review of hospital admission procedures for children undergoing adenotonsillectomy is urgently needed. Operation times for children should be known well in advance so that they may be fed at least up to four hours before operation. Further trial should be given to using metoclopramide to allow children to drink up to one hour before anaesthesia, ${ }^{5}$ a distinct advantage for morning lists and day cases.

I thank Mr R J Sellick for permission to report this case, and Dr R D Jones and Dr C G D Brook for help and encouragement.

1 Bevan, J C, and Burn, M C, British fournal of Anaesthesia, 1973, 45, 115.

2 Frantz, I D, Medina, M, and Taeusch, $H$ W, fournal of Pediatrics, 1975, 87, 417.

3 Cornblath, M, and Schwartz, R, Disorders of Carbohydrate Metabolism in Infancy, p 193. Philadelphia, Saunders, 1966.

4 Thomas, D K M, British fournal of Anaesthesia, 1974, 46, 66.

- Fry, E N S, and Ibrahim, A A, British Medical fournal, 1974, 3, 808.

United Norwich Hospitals, Norwich, Norfolk

C J H KELNAR, MB, DCH, senior house officer, paediatrics (present address: Department of Paediatrics, Middlesex Hospital, London WIN 8AA)

\section{Non-bacterial thrombotic endocarditis in early cancer}

In some $90 \%$ of cases non-bacterial thrombotic endocarditis (NBTE) as a complication of cancer does not occur until metastases are widespread. ${ }^{2}$ Our experience of two patients who died of unsuspected NBTE when the small associated tumour had not metastasised beyond adjacent lymph nodes impressed on us the clinical significance of what is usually regarded as an essentially pathological diagnosis.

\section{Case reports}

Case 1-A woman aged 58 was admitted with chest pain and haemoptysis after six weeks' warfarin treatment for deep vein thrombosis of the left leg. She had a prothrombin ratio of 1.5 , developed mental confusion and left hemiparesis, and had raised fibrin degeneration products in serum and a platelet count of $90 \times 10^{9} / 1\left(90000 / \mathrm{mm}^{3}\right)$. Heparin was given. Her mental state deteriorated and she developed progressive pulmonary infarction She died on day 27 . The necropsy findings were adenocarcinoma of body of pancreas $2 \mathrm{~cm}$ in diameter; adjacent lymph nodes enlarged and infiltrated by tumour; friable vegetations on mitral valve and lying free in left ventricular cavity (see fig); right renal and both common iliac veins thrombosed; and infarcts of lungs, brain, and right kidney.

Case 2-A man aged 40 was admitted with haemoptysis after three months' dyspnoea and calf pains. He smoked $\mathbf{4 0}$ cigarettes a day. Hodgkin's disease had been treated five years previously by radiotherapy and was now presumed inactive, though a new chest radiograph showed enlarged right hilum. Bilateral deep vein thrombosis was diagnosed and warfarin treatment started. There was steady proximal extension of thrombosis, with three major pulmonary infarctions. Diagnosis of disseminated intravascular coagulation on day 8 prompted change to heparin infusion, but 72 hours later he died of anterolateral myocardial infarction. Necropsy showed minute papillary adenocarcinoma of right upper lobe bronchus, involving hilar lymph nodes; no evidence of Hodgkin's disease; large verrucous vegetations on mitral valve; and occlusion of anterior descending branch, left coronary artery. Heart, lungs, and kidneys were extensively infarcted.

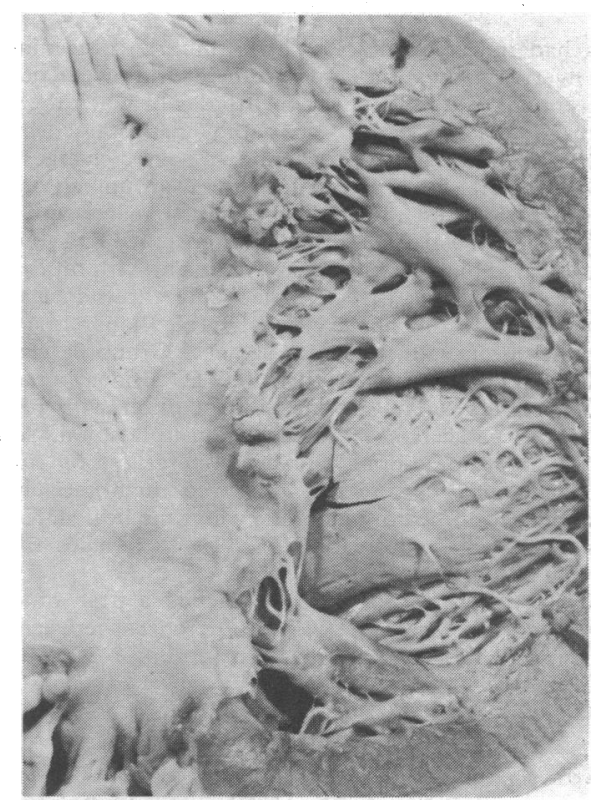

Non-bacterial thrombotic endocarditis in early cancer.

\section{Comment}

Although presenting with the familiar features of deep vein thrombosis of the leg, each case pursued an atypical course. The thrombosis progressed; causing repeated pulmonary embolism, and was associated not only with disseminated intravascular coagulation but àlso with episodes that suggested recurrent systemic embolism. Underlying neoplasia was suspected, and in case 2 all but proved. Nevertheless, the investigations necessary for a conclusive diagnosis were prevented by deterioration which, in retrospect, must be attributed largely to NBTE.

In some cases of NBTE due to non-malignant disease and in the $10 \%$ of cancer patients for whom, like these two, resection of the tumour is possible, death might be averted if the valvular lesion could be identified in life. Despite its well documented pathology, however, and the firm place it has gained among the complications of cancer, NBTE remains almost exclusively a necropsy diagnosis. This may be because one, or even two, of the three components accepted as being essential for diagnosis - an appropriate underlying disease, a cardiac murmur, and multiple systemic embolism ${ }^{3}$-are absent from the clinical picture. New murmurs arise in no more than $20 \%$ of patients and the more amenable to surgery the underlying tumour the less likely it is to be found by the simpler investigations.

We therefore propose the following revised criteria for diagnosing NBTE: (a) venous thrombosis accompanied by features suggesting systemic as well as pulmonary infarction; (b) progression despite anticoagulant treatment; $(c)$ either no apparent origin for the systemic emboli or else a cardiac murmur in the presence of persistently negative blood culture. If a presumptive diagnosis could be made with these criteria, developing a non-invasive technique to confirm it would enable corrective surgery to be considered for any patient in whom disseminated malignancy or other irreversible disease had been excluded with reasonable certainty.

1 Guinn, G A, Ayala, A, and Liddicoat, J, Chest, 1973, 64, 26.

2 Rosen, P, and Armstrong, D, American Fournal of Medicine, 1973, 54, 23.

- McKay, D G, Disseminated Intravascular Coagulation. An Intermediary Mechanism of Disease, p 369. New York, Harper and Row, 1965.

Department of Medicine, Lister Hospital, Stevenage, Herts SG1 4AB P STUDDY, LRCP, MRCs, senior house officer (present address: Royal Free Hospital, London NW3)

J M T WILLOUGHBY, DM, MRCP, consultant physician 